\title{
Evaluation of Quality Indicators in an Indian Intensive Care Unit Using "CHITRA" Database
}

\author{
Kiran Kumar Gudivada, Bhuvana Krishna, Sampath Sriram \\ Department of Critical Care Medicine, St. John's Medical College and Hospital, Bengaluru, Karnataka, India
}

\section{Abstract}

Background: Quality indicators (QIs) are essential for maintaining quality of care in the critically ill. The Indian Society of Critical Care Medicine proposed benchmarks and enabled Indian Intensive Care Units (ICUs) to capture data in an electronic database: Customized Health in Intensive Care Trainable Research and Analysis (CHITRA) tool. The purpose of this study is to report QIs in an Indian ICU using this database. Materials and Methods: Data from patients admitted to ICU between October 2015 and January 2017 were entered into CHITRA. The following QIs were analyzed: standardized mortality ratio (SMR), length of ICU stay (LOS-ICU), pressure ulcer (PU) rate, patient fall rate (FR), ICU readmission rate, reintubation rate, ventilator-associated condition (VAC), central line-associated bloodstream infection (CLABSI), catheter-associated urinary tract infection (CAUTI), and iatrogenic pneumothorax rate. Results: A total of 2642 patient's information was suitable for analysis. Median age of ICU admission was 53 years (interquartile range [IQR]: 36-65), with a mean APACHE score of 18 (SD 7.7). Median LOS-ICU was 3 days (IQR 2-6) and SMR was 1.1 (95\% confidence interval 1.05-1.38). Pneumothorax rate, PU rate, and FR were $2.6,4.1$, and 0.3 per 1000 respectively, whereas readmission rate was $0.7 \%$ and reintubation rate was $3.5 \%$. VAC, CLABSI, and CAUTI were 8.5, 23, 3.1 per 1000 ventilator and catheter days, respectively. Conclusion: This study has successfully evaluated a range of QIs in a mixed ICU of a tertiary hospital utilizing CHITRA database.

Keywords: Benchmark, critically ill, intensive care, quality indicators

\section{INTRODUCTION}

Quality indicators (QIs) have gained importance in care of the critically ill due to the vulnerable nature of patients, complexity of care delivery processes, and significant economic and workforce burden to caregivers. The concept "quality" had evolved in the eighteenth century in the backdrop of the Crimean war, ${ }^{[1]}$ where the importance of hand hygiene and sanitation were identified. The release of American College of Surgeon's "Minimum Hospital Standard" statement in $1919^{[2]}$ was seminal to the development of modern hospital standards. Other significant milestones in the path to better quality have been the establishment of Joint Commission on the Accreditation of Hospitals, ${ }^{[3]}$ Williamson's concept of "achievable benefit not achieved," "[4] and the Donabedian model ${ }^{[5]}$ on quality of care.

Quality of care in the Intensive Care Units (ICUs) in developed countries has been well described. ${ }^{[3,6,7]}$ In the year 2008, a task force was constituted by the Indian Society of Critical Care Medicine (ISCCM) to formulate quality control in Indian ICUs,

\begin{tabular}{|l|l|}
\hline \multicolumn{2}{|c|}{ Access this article online } \\
\hline Quick Response Code: & Website: \\
\hline & www.ijccm.org \\
\cline { 2 - 2 } & \\
\hline
\end{tabular}

and benchmarks and standards were proposed. ${ }^{[8]}$ However, data on the use and applicability of these indicators have not been well described in India.

Currently, there is scanty literature available on quality of care in ICUs across India. The use of electronic health records (EHRs) could help circumvent this issue. However, projections indicate that by the year 2020, only $1.5 \%$ of Indian hospitals will have EHRs of the highest level (Stage 7), which can provide automated data analytics. ${ }^{[9]}$

To address this issue, the ISCCM in 2014 took the initiative to enable all Indian ICUs to capture and store relevant data in a systematic manner in an electronic database: Customized Health in Intensive Care Trainable Research and Analysis

Address for correspondence: Dr. Bhuvana Krishna, Department of Critical Care Medicine, St. John's Medical College and Hospital, Bengaluru - 560 034, Karnataka, India. E-mail: bhuvana.11@gmail.com

This is an open access article distributed under the terms of the Creative Commons Attribution-NonCommercial-ShareAlike 3.0 License, which allows others to remix, tweak, and build upon the work non-commercially, as long as the author is credited and the new creations are licensed under the identical terms.

For reprints contact: reprints@medknow.com

How to cite this article: Gudivada KK, Krishna B, Sriram S. Evaluation of quality indicators in an Indian intensive care unit using "CHITRA" database. Indian J Crit Care Med 2017;21:841-6. 
tool ("CHITRA"). ${ }^{[10]}$ This database did not require a sophisticated EHR and aimed to be an independent system. The aim of the current study was to report QIs in a single ICU using the CHITRA database and also assess feasibility of collecting data as part of routine work.

\section{Materials and Methods}

The approval for this study was obtained from the Institutional Ethics Committee. Patients admitted to the ICU between October 2015 and January 2017 were included in the study, and data were captured at bedside computers in which CHITRA database had been installed. Informed consent was obtained from the legally authorized representative at admission. Material for this study was abstracted from the CHITRA database.

At admission, patient-specific diagnostic data were entered by medical staff. Ventilation and procedural and safety data were entered daily by nursing staff. Data necessary for calculating severity of illness were captured by ICU secretarial staff, who had been trained for data entry. At discharge, outcomes were captured by secretarial and senior nursing staff. Microbiological data were independently extracted from the Hospital Laboratory Information System. Formal training was given to medical and nursing staff to ensure that data entry into CHITRA was part of their daily work pattern. Random checks were done to ensure completeness and accuracy of data capture.

\section{Outcomes measured}

The following metrics from the QIs as suggested by the ISCCM quality guidelines ${ }^{[8]}$ were collated: (1) standardized mortality ratio (SMR) (2) length of ICU stay (LOS-ICU), (3) pressure ulcer (PU) rate, (4) patient fall rate (FR), (5) ICU readmission rate, (6) reintubation rate, (7) ventilator-associated condition (VAC), (8) central line-associated bloodstream infection (CLABSI) rate, (9) catheter-associated urinary tract infection (CAUTI) rate, and (10) iatrogenic pneumothorax rate.

\section{Statistical analysis}

Data from CHITRA database were analyzed using STATA ${ }^{\mathrm{TM}}$ v14 (StataCorp. 2015. Stata Statistical Software: Release 14., StataCorp LP, College Station, TX, USA). QIs were calculated using standard formulae, which have been detailed in the electronic supplementary materials (ESM). The SMR was calculated using an internally generated predictive model based on prior data specific to the ICU. The coefficients and constants of the predictive model and methods to generate SMR have been detailed in the ESM. Iatrogenic pneumothorax rates, patient FRs, and decubitus ulcer rates were extracted from the database using the appropriate Systematized Nomenclature of Medicine-Clinical Terms codes which have been described in the ESM. LOS, VAC, CLABSI, CAUTI, and reintubation rates were calculated using scripts and standard formulae, which have been described in the ESM.

\section{RESULTS}

There were 2689 admissions to the ICU in the study period, of which 2642 patients (98\%) had data which were captured in the CHITRA database and suitable for analysis. Demographic details are shown in Table 1.

Table 2 summarizes QIs over 3 monthly periods. LOS-ICU ranged from 1 to 93 days, with quarterly medians ranging from 3 to 4 days, and overall median ICU stay was 3 days (interquartile range [IQR] 2-6). The SMR was $1.1(95 \%$ confidence interval 1.05-1.38), with one quarter having an SMR of 1.4. The total iatrogenic pneumothoraces were seven and rate of pneumothorax per 1000 ICU admissions ranged from 0 to 5.4 with a mean of 2.6 per $1000 \mathrm{ICU}$ admissions. Before ICU admission, there were 44 PUs, and 11 patients acquired PU in ICU with quarterly incidence ranging from 0 to 7 and with overall incidence of 4.1 per 1000 admissions. Of 11 patients, eight had a single PU, two patients had two PUs, and one had four PUs. In our ICU, total readmissions within $24 \mathrm{~h}$ of discharge were $18(0.7 \%)$. We noted only one fall in our study period, with FR of 0.3 per 1000 patient days (pd).

Of the 2642 patients, a total of 1075 (41\%) received mechanical ventilation [Table 3]. Of these 37 (3.4\%) patients were reintubated within $48 \mathrm{~h}$ of extubation. VACs were calculated per 1000 ventilator days (vd) and there were 37 VACs for $4347 \mathrm{vd}$, accounting to 8.5 per $1000 \mathrm{vd}$. There were no VACs recorded in first 3 months of the study period due to logistical issues in standardization of data collection. Table 3 also displays data of CLABSI and CAUTI over the study period. There were 23 and 3.1, CLABSI and CAUTI per 1000 catheter days (cd), respectively. However, the total cd for CLABSI and CAUTI were 10,210 and 11,203 , respectively.

\begin{tabular}{lc}
\hline \multicolumn{2}{l}{ Table 1: Details of patients admitted to Intensive Care } \\
Unit \\
\hline Variables & Values \\
\hline Age, years (IQR) & $53(36-65)$ \\
Gender (female/male) & $976 / 1666$ \\
APACHE II score (SD, range) & $18(7.7,2-53)$ \\
LOD score (SD, range) & $6.4(3.5,0-18)$ \\
Nursing ratio (nurses/patients) & $1: 2$ \\
Doctor:patient ratio & $1: 10$ \\
Outcome (\%) & \\
Survived & 70 \\
Died ICU & 19.6 \\
DAMA & 10.4 \\
Source of admission (\%) & \\
Emergency & 47 \\
Inpatient & 34 \\
Operation theater & 5 \\
Others & 14 \\
\hline APACHE: Acte Physion
\end{tabular}

APACHE: Acute Physiology and Chronic Health Evaluation; SD: Standard deviation; ICU: Intensive Care Unit; IQR: Interquartile range; DAMA: Discharge against medical advice; LOD: Logistic Organ Dysfunction Score 


\begin{tabular}{|c|c|c|c|c|c|c|c|}
\hline Month & $N$ & $\begin{array}{l}\text { LOS, median } \\
\text { (IQR) }\end{array}$ & $\begin{array}{l}\text { SMR, mean } \\
(95 \% \mathrm{Cl})\end{array}$ & $\begin{array}{l}\text { Pneumothorax, } \\
n \text { (per 1000) }\end{array}$ & $\begin{array}{l}\text { Pressure ulcer, } \\
n \text { (per 1000) }\end{array}$ & $\begin{array}{c}\text { Readmission, } \\
n(\%)\end{array}$ & $\begin{array}{c}\text { Falls, } n \text { (per } \\
1000 \text { pd) }\end{array}$ \\
\hline October-December 2015 & 332 & $4(3-6)$ & $1.0(0.8-1.2)$ & 0 & - & $1(0.3)$ & $1(3)$ \\
\hline January-March & 492 & $4(2-7)$ & $1.4(1.2-1.6)$ & $2(4)$ & $7(14)$ & $4(0.8)$ & - \\
\hline April-June & 548 & $3 \cdot 5(2-6)$ & $1.2(1.1-1.4)$ & $3(5.4)$ & $2(3.6)$ & $2(0.4)$ & - \\
\hline July-September & 640 & $3(2-6)$ & $1.1(0.9-1.2)$ & $2(3.1)$ & $1(1.5)$ & $4(0.6)$ & - \\
\hline October-December 2016 & 630 & $3(2-6)$ & $1.0(0.8-1.2)$ & 0 & $1(1.6)$ & $7(1.1)$ & - \\
\hline Total & 2642 & $\begin{array}{c}3(2-6) \\
\text { Range (1-93) }\end{array}$ & $\begin{array}{c}1.1(1.05-1.38) \\
(n=1463)\end{array}$ & $7(2.6)$ & $11(4.1)$ & $18(0.7)$ & $1(0.3)$ \\
\hline
\end{tabular}

$N$ : Number of patients; LOS: Length of stay ICU; SMR: Standardized mortality ratio; IQR: Interquartile range; CI: Confidence interval; $n$ : Indicate exact number of events; ICU: Intensive Care Unit

\begin{tabular}{|c|c|c|c|c|c|c|c|c|}
\hline \multirow[t]{2}{*}{ Month } & \multirow[t]{2}{*}{$N$} & \multirow{2}{*}{$\begin{array}{c}\text { Reintubation }<48 \mathrm{~h} \\
\begin{array}{c}\text { Reintubated/ } \\
\text { intubated (\%) }\end{array}\end{array}$} & \multicolumn{2}{|c|}{ VAC } & \multicolumn{2}{|c|}{ CLABSI } & \multicolumn{2}{|c|}{ CAUTI } \\
\hline & & & $\begin{array}{l}n / \text { ventilator } \\
\text { days }\end{array}$ & $\begin{array}{c}\text { Per } 1000 \\
\text { ventilator days }\end{array}$ & $\begin{array}{l}n / \text { catheter } \\
\text { days }\end{array}$ & $\begin{array}{c}\text { Per } 1000 \\
\text { catheter days }\end{array}$ & $\begin{array}{l}n / \text { catheter } \\
\text { days }\end{array}$ & $\begin{array}{l}\text { Per } 1000 \\
\text { catheter days }\end{array}$ \\
\hline October-December 2015 & 332 & $4 / 118(3.4)$ & - & - & $36 / 1233$ & 29 & $1 / 1385$ & 0.7 \\
\hline January-March & 492 & $6 / 196(3)$ & $3 / 733$ & 4 & $57 / 2234$ & 25 & $6 / 2376$ & 2.5 \\
\hline April-June & 548 & $9 / 253(3.5)$ & $12 / 1314$ & 9 & $73 / 2284$ & 31 & $7 / 2481$ & 2.8 \\
\hline July-September & 640 & 8/261 (3) & $15 / 1174$ & 12.7 & $41 / 2452$ & 16 & $11 / 2698$ & 4 \\
\hline October-December 2016 & 630 & $10 / 247(4)$ & $7 / 1126$ & 6.2 & $33 / 2007$ & 16 & $10 / 2263$ & 4.4 \\
\hline Total & 2642 & $37 / 1075(3.5)$ & $37 / 4347$ & 8.5 & $240 / 10,210$ & 23 & $35 / 11,203$ & 3.1 \\
\hline
\end{tabular}

$N$ : Number of patients; $n$ : Indicate exact number of events; VAC: Ventilator-associated condition; CLABSI: Central line-associated bloodstream infection; CAUTI: Catheter-associated urinary tract infection

\section{Discussion}

This is the first single-center report on QIs, derived from the CHITRA database. CHITRA project had been initiated in the year 2014, as an endeavor to capture and scrutinize QIs and thereby attempting to standardize delivery of care in Indian ICUs and provide national benchmarks. Our results provide a range of QIs analyzed from a single center in contrast to earlier publications, which have focused on particular subsets of performance indicators. ${ }^{[1]}$

The median LOS in our ICU was 3 days (IQR 2-6), which was close to benchmark of 3.3 days. SMR is an objective way to evaluate the performance of an ICU and provides an appropriate estimate to compare outcomes between different units by adjusting disease severity and type. ${ }^{[12]}$ SMR is influenced by geographical location and spectrum of cases in a particular region; hence while benchmarking, these factors should be considered. ${ }^{[13]}$ SMRs published from Indian ICUs should be interpreted cautiously, as a well-validated scoring system has not been published for Indian ICUs and it is known that scoring systems perform poorly when applied in environments different from where they were derived.

Iatrogenic pneumothorax is one of the morbidity indicators that indicate patient safety. In a retrospective cohort study by John and Seifi, ${ }^{[14]}$ they described a higher incidence of pneumothoraces in teaching, compared to nonteaching hospitals (1.3 vs. 1.0). Similar to this, our results from a tertiary teaching hospital showed an incidence of 2.6 , which was double the incidence noted in western teaching hospitals. Multiple factors such as level of training of person performing the procedure, degree of supervision, patient-related factors such as comorbidities, severity of illness, type of patients admitted to tertiary hospitals, and also availability of equipment (ultrasound machines) could have influenced the outcome.

Shea ${ }^{[15]}$ classified PU into five grades. By including redness or erythema as grade 1, this classification has the potential to identify evolving ulcer at early stages. We used the same classification in our unit, and the incidence of PU was 4.1 per 1000 cases, which was better than western literature $(22 / 1000){ }^{[16]}$ These results are not surprising as preexisting PUs have been excluded and more than $34 \%$ of the admissions are from inpatient wards or other hospitals and preexisting PUs can thus be attributed to the original healthcare facility.

FR in our study was 0.3 per $1000 \mathrm{pd}$, which is markedly lower than the standard 8.46 as quoted by Barnett and House. ${ }^{[17]}$ There have been wide variations in the incidence of FRs in various studies, ranging from 3.3 to 11 per $1000 \mathrm{pd}$. This is probably due to heterogeneity in study population. ${ }^{[18]} \mathrm{FR}$ is a significant safety concern and can lead to patient and family dissatisfaction, morbidity, and rarely mortality. Implementing protocolized care by multidisciplinary healthcare teams may reduce risk of falls in ICUs. ${ }^{[17]}$

ICU readmission may be related to quality of care in step-down units or errors in assessment for suitability of transfer out 
of patients from ICU. ${ }^{[19]}$ Readmission rates of $4 \%-6 \%$ have been published, ${ }^{[20,21]}$ and lower rates could indicate long LOS in ICU and increased risk of nosocomial infections. Higher readmission rates may signify premature ICU discharges and such patients when readmitted have an increased LOS with 1.5-10 times greater mortality. ${ }^{[19,21,22]}$ Our lower readmission rates $(0.7$ vs. $4 \%-6 \%)$ could be explained by financial constraints and perceived poor prognosis that could have influenced caregivers to opt for continuing care in the ward.

Reintubation rates in this study were also lower than that described by McMillan and Delgado (3.5 vs. 12\%). ${ }^{[6,23]} \mathrm{A}$ near-zero reintubation rate may not be desirable as this may result in prolonged weaning or excessive tracheostomy rates. The optimal reintubation rate to be considered remains still an enigma. A balance should be maintained between the negative consequences of early extubation, resulting in reintubation, and the sequelae of delayed liberation from mechanical ventilation, resulting in higher incidence of nosocomial pneumonia and increased LOS-ICU. ${ }^{[2]}$ In a large prospective observational study, $12.2 \%$ patients were reintubated within $48 \mathrm{~h}$ of extubation. ${ }^{[25]}$ Lower reintubations in this study could be due to the following reasons: We routinely use ultrasonography to determine the fitness for extubation, especially in patients who are at high risk of extubation failure. ${ }^{[26]}$ Second, we use prophylactic noninvasive ventilation in extubated patients with type 2 respiratory failure, congestive heart failure and patients who had weaning difficulties before extubation. ${ }^{[27]}$ Third, we consider early tracheostomy in patients who are likely to fail extubation (e.g., chronic neurological/neurosurgical patients) although this approach is still debatable.

Nosocomial infections impose both financial and resource burdens. Commonly monitored nosocomial indicators are VAE, CLABSI, and CAUTI. In 2002, Centers for Disease Control and Prevention (CDC) defined ventilator-associated pneumonia (VAP) depending on specified clinical and radiological criteria. ${ }^{[28]}$ Due to lack of consistency in the

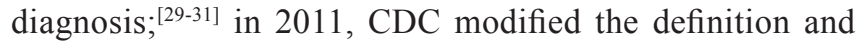
grouped all conditions that lead to impaired oxygenation and termed it as VAE. ${ }^{[32]}$ It was designed to capture the entire spectrum of infectious and noninfectious events that lead to impaired oxygenation and was implemented in the National Healthcare Safety Network (NHSN) in January 2013 for clinical practice. VAE also represents one of the patient safety indicators and is an important cause of morbidity and mortality. ${ }^{[33]}$ We have calculated VAC in the hierarchical definition of VAE as we have limited data available on daily white blood cell count, culture reports, and other clinical parameters to define IVAC, possible and probable VAP. VAC incidence in this study was comparatively better than the International Nosocomial Infection Control Consortium (INICC) surveillance data (8.5 vs. 19.5) from ICUs of Latin America, Asia, Africa, and Europe. ${ }^{[34]}$ Whereas, it is comparable with NHSN 2014 reported VAE incidence of 2-11 per $1000 \mathrm{vd} .^{[35]}$ We adopted routine practice of VAP prevention bundles as proposed by Institute for Healthcare Improvement to minimize the risk. ${ }^{[36]}$ We postulated that universal use of closed suction systems might have contributed to lower incidence of VAE.

CLABSI and CAUTI are two other commonly adopted nosocomial QIs. The rate of CLABSI in our ICU was 23 per $1000 \mathrm{~cd}$, which was 3-5 folds higher than INICC and NHSN reported rates, 9.2 and $2-5$ per $1000 \mathrm{~cd}$, respectively. ${ }^{[34,37]}$ CAUTI incidence in this study was 3.1 per $1000 \mathrm{~cd}$, which was comparable to INICC (4 per $1000 \mathrm{~cd}$ ) and NHSN (6 per $1000 \mathrm{~cd})$ surveillance studies. ${ }^{[34,37]}$ As compared to VAE and CAUTI rates, our CLABSI rates were higher than the published benchmarks. The probable explanations could be that there were relatively more manipulations of the central venous catheters by our health care providers, in contrast to urinary drainage and endotracheal suction systems which were closed systems. Femoral location of central lines may contribute to increased CLABSI rates; however, despite more than half of the central line days being femoral (55\%), the proportion of CLABSI attributable to femoral central lines were not significantly different (22.5 femoral vs. 24.6 nonfemoral per $1000 \mathrm{~cd}, P=0.5$ Fisher's exact test).

We have compared performance of QIs in various Indian studies with our results [Table 4]. There is no large single-center study, which has evaluated a range of QIs. To our knowledge, QIs such as iatrogenic pneumothorax and FR in Indian ICUs have not been widely published. A wide variation in the performance of QIs in Indian ICUs is shown in Table 4. This is possibly due to heterogeneity of study population. For instance pressure ulcer rates were studied in only one study by Babu et al., ${ }^{[51]}$ where the incidence was 31 per $1000 \mathrm{pd}$ in a dedicated neuro-surgical ward, and the higher rate could be attributed to the specialized subset of patients in this study. Median LOS-ICU in a large multicenter trial was 6 days whereas median LOS-ICU in this study was 3 days. ${ }^{[38]}$

Our study which included mixed medical and surgical population $(n=2642)$ had a readmission rate of $0.7 \%$, whereas readmission rate $(<48 \mathrm{~h})$ in the study by Amin et al., ${ }^{[39]}$ which included 1190 surgical patients was two folds higher ( 1.4 vs. $0.7 \%$ ). This may be due to a lower cutoff chosen in our study for readmissions ( $<24 \mathrm{~h}$ of discharge from ICU). Karthikeyan et al. $^{[40]}$ reported a reintubation rate of $29 \%$, where $41 \%$ of patients had poisoning and envenomation, explaining the higher reintubation rate as compared to our study (29 vs. $3.5 \%$ ).

There are numerous studies published on incidence of VAP, CLABSI, and CAUTI with varying incidence. ${ }^{[41-45]}$ Earlier studies on VAP incidence used the clinical pulmonary infection score, ${ }^{[42-44,46,47]}$ which is known to have unpredictable sensitivity and specificity, ${ }^{[31,47]}$ whereas a recent study by Mathai et al. ${ }^{[41]}$ had not specified the exact criteria used to define VAP. We have calculated VAC using recent CDC guidelines. ${ }^{[32]}$

Dasgupta et al. ${ }^{[43]}$ and Datta et al. ${ }^{[44]}$ reported CLABSI and CAUTI rates using $2008 \mathrm{CDC}$ NHSN surveillance 


\begin{tabular}{lccc}
\hline \multicolumn{1}{l}{ Table 4: Comparison of performance of quality indicators } & & \\
\hline Quality indicator & Results from our study & Other Indian studies & Benchmarks (international) \\
\hline LOS, median (IQR) & $3(2-6)$ & $6,4.5^{[38-50]}$ & $3.3^{[23]}$ \\
Pneumothorax (per 1000) & 2.6 & - & $0.9-1.4^{[14]}$ \\
Pressure ulcer (per 1000) & 4.1 & $31^{[51]}$ & $22^{[16]}$ \\
Readmission (<24 h) (\%) & 0.7 & $1 \cdot 4(<48 \mathrm{~h})^{[39]}$ & - \\
Falls (per 1000 pd) & 0.3 & $26^{[6,23]}$ \\
Reintubation (<48 h) (\%) & 3.5 & $3.3-11^{[18]}$ \\
VAC (per 1000 ventilator days) & 8.5 & $12^{[6,23]}$ \\
CLABSI (per 1000 catheter days) & 23 & $40.1,31.7,26.6,6.04^{[41-44]}$ & $2-11$ and $19.5^{[34,35]}$ \\
CAUTI (per 1000 catheter days) & 3.1 & $2.46,13.86^{[43,44]}$ & $2-5$ and $9.2^{[34,37]}$ \\
\hline
\end{tabular}

LOS: Length of stay ICU; IQR: Interquartile range; VAC: Ventilator-associated condition; CLABSI: Central line-associated bloodstream infection; CAUTI: Catheter-associated urinary tract infection; ICU: Intensive Care Unit

guidelines. ${ }^{[47]}$ The incidence of CLABSI in Dasgupta et al. ${ }^{[43]}$ and Datta et al.${ }^{[4]}$ was 2.46 and 13.86 per $1000 \mathrm{~cd}$, respectively, and CAUTI rates in these studies were 7.44 and 9.08 per $1000 \mathrm{~cd}$, respectively. We followed recent criteria to define $\mathrm{CLABSI}^{[48]}$ and CAUTI ${ }^{[49]}$ to improve the diagnostic accuracy and found the incidence as 23 and 3.1 per $1000 \mathrm{~cd}$, respectively. The number of patients included in prior studies from India was less than the present study.

During the study period, $98 \%$ of all admissions had data successfully captured and suitable for generation of quality metrics. This has demonstrated the feasibility of collection of quality data on a routine basis. This has been possible using the CHITRA system which has been developed at a modest cost of INR 3,500,000 (USD 55000). The EHR penetration in developing countries is likely to be low over the next few years; due to economic constraints, there is a role for systems such as CHITRA. Projects such as CHITRA if implemented in a significant number of Indian ICUs can lead to the development of national benchmarks, which will contribute to better quality and safety.

This study has limitations, and being a single-center study, the results cannot be easily generalized. All QIs as suggested by the ISCCM could not be captured in this study. Medication errors and adherence to protocols were metrics which required significant contributions in time from personnel, which was difficult to implement. Calculating the denominator for needle stick injuries was also difficult to execute successfully. The SMR has been calculated from an internally derived scoring system. In the absence of a validated general purpose Indian scoring system, the SMR can only be used as an internal quality metric.

\section{Conclusion}

This study has successfully evaluated a range of QIs in a mixed ICU of a tertiary hospital from India. This study has also demonstrated the utility of the CHITRA system and the feasibility of generating QIs as a part of routine care.

\section{Financial support and sponsorship}

Nil.

\section{Conflicts of interest}

There are no conflicts of interest.

\section{References}

1. Small H. A Brief History of Florence Nightingale: And Her Real Legacy, a Revolution in Public Health. London, UK: Little, Brown Book Group; 2017.

2. Wright JR Jr. The American College of Surgeons, minimum standards for hospitals, and the provision of high-quality laboratory services. Arch Pathol Lab Med 2017;141:704-17.

3. The Joint Commission - Hospital Accreditation (JCAH). Available from: http://www.jointcommission.org/accreditation/hospitals.aspx. [Last accessed on 2017 May 15].

4. Williamson JW, Wilson R. Assessing and Improving Health Care Outcomes: The Health Accounting Approach to Quality Assurance. Cambridge, MA: Ballinger Publication Co.; 1978.

5. Donabedian A. The quality of care. How can it be assessed? JAMA 1988;260:1743-8.

6. Delgado M, Pericas L, Moreno J, Torra L, Varela J, Suero F, Anuncibay P, Guiseris J. Quality indicators in critically ill patients. Sociedad Española de Medicina Intensiva Crítica y Unidades Coronarias (SEMISYUS); 2005.

7. The Australian Council on Healthcare Standards (ACHS). Available from: http://www.safetyandquality.gov.au/wp-content/uploads/2012/02/ INTENSIVE_CARE_2011.pdf. [Last accessed on 2017 May 15].

8. Ray B, Samaddar DP, Todi SK, Ramakrishnan N, John G, Ramasubban S, et al. Quality indicators for ICU: ISCCM guidelines for ICUs in India. Indian J Crit Care Med 2009;13:173-206.

9. Sharma M, Aggarwal H. EHR adoption in India: Potential and the challenges. Indian J Sci Technol 2016;9:34.

10. CHITRA - Customized, Health in Intensive Care, Trainable Research and Analysis Tool. Available from: http://www.isccm.org/chitra. aspx. [Last accessed on 2017 May 15].

11. Mehta Y, Jaggi N, Rosenthal VD, Kavathekar M, Sakle A, Munshi N, et al. Device-associated infection rates in 20 cities of India, data summary for 2004-2013: Findings of the international nosocomial infection control consortium. Infect Control Hosp Epidemiol 2016;37:172-81.

12. Afessa B, Gajic O, Keegan MT. Severity of illness and organ failure assessment in adult Intensive Care Units. Crit Care Clin 2007;23:639-58.

13. Glance LG, Osler T, Shinozaki T. Effect of varying the case mix on the standardized mortality ratio and $\mathrm{W}$ statistic: A simulation study. Chest 2000;117:1112-7.

14. John J, Seifi A. Incidence of iatrogenic pneumothorax in the United States in teaching vs. Non-teaching hospitals from 2000 to 2012. J Crit Care 2016;34:66-8.

15. Shea JD. Pressure sores: Classification and management. Clin Orthop Relat Res 1975;112:89-100.

16. Sharp Health Care (SHARP). Malcolm Baldrige National Quality Award Application; 2007. Available from: http://www.patapsco.nist. gov/Award_Recipients/PDF_Files/2007_Sharp_Application_Summary. 
pdf. [Last accessed on 2017 May 13].

17. Barnett K, House R. Reducing Patient Falls Project. Dostopnona; 2008. Available from: http://www.premierinc.com/safety/topics/falls/ downloads/E-14-falls-project-uk pdf (1510 2009). [Last accessed on 2017 May 15].

18. Bouldin EL, Andresen EM, Dunton NE, Simon M, Waters TM, Liu M, et al. Falls among adult patients hospitalized in the United States: Prevalence and trends. J Patient Saf 2013;9:13-7.

19. Chen LM, Martin CM, Keenan SP, Sibbald WJ. Patients readmitted to the Intensive Care Unit during the same hospitalization: Clinical features and outcomes. Crit Care Med 1998;26:1834-41.

20. Rosenberg AL, Watts C. Patients readmitted to ICUs: A systematic review of risk factors and outcomes. Chest 2000;118:492-502.

21. Metnitz PG, Fieux F, Jordan B, Lang T, Moreno R, Le Gall JR, et al. Critically ill patients readmitted to Intensive Care Units - Lessons to learn? Intensive Care Med 2003;29:241-8.

22. Cooper GS, Sirio CA, Rotondi AJ, Shepardson LB, Rosenthal GE. Are readmissions to the Intensive Care Unit a useful measure of hospital performance? Med Care 1999;37:399-408.

23. McMillan TR, Hyzy RC. Bringing quality improvement into the Intensive Care Unit. Crit Care Med 2007;35:S59-65.

24. Epstein SK, Ciubotaru RL, Wong JB. Effect of failed extubation on the outcome of mechanical ventilation. Chest 1997;112:186-92.

25. Esteban A, Anzueto A, Frutos F, Alía I, Brochard L, Stewart TE, et al. Characteristics and outcomes in adult patients receiving mechanical ventilation: A 28-day international study. JAMA 2002;287:345-55.

26. Mayo P, Volpicelli G, Lerolle N, Schreiber A, Doelken P, Vieillard-Baron A, et al. Ultrasonography evaluation during the weaning process: The heart, the diaphragm, the pleura and the lung. Intensive Care Med 2016;42:1107-17.

27. Nava S, Gregoretti C, Fanfulla F, Squadrone E, Grassi M, Carlucci A, et al. Noninvasive ventilation to prevent respiratory failure after extubation in high-risk patients. Crit Care Med 2005;33:2465-70.

28. Raoof S, Baumann MH, Critical Care Societies Collaborative, consisting of the leadership of the American Association of Critical-Care Nurses, the American College of Chest Physicians, the American Thoracic Society, and the Society of Critical Care Medicine. Ventilator-associated events: The new definition. Am J Crit Care 2014;23:7-9.

29. Klompas M. Interobserver variability in ventilator-associated pneumonia surveillance. Am J Infect Control 2010;38:237-9.

30. Klompas M, KulldorffM, PlattR. Risk of misleading ventilator-associated pneumonia rates with use of standard clinical and microbiological criteria. Clin Infect Dis 2008;46:1443-6.

31. Zilberberg MD, Shorr AF. Ventilator-associated pneumonia: The clinical pulmonary infection score as a surrogate for diagnostics and outcome. Clin Infect Dis 2010;51 Suppl 1:S131-5.

32. Magill SS, Klompas M, Balk R, Burns SM, Deutschman CS, Diekema $\mathrm{D}$, et al. Developing a new, national approach to surveillance for ventilator-associated events. Am J Crit Care 2013;22:469-73.

33. Warren DK, Shukla SJ, Olsen MA, Kollef MH, Hollenbeak CS, Cox MJ, et al. Outcome and attributable cost of ventilator-associated pneumonia among Intensive Care Unit patients in a suburban medical center. Crit Care Med 2003;31:1312-7.

34. Rosenthal VD, Maki DG, Mehta A, Alvarez-Moreno C, Leblebicioglu H, Higuera $\mathrm{F}$, et al. International nosocomial infection control consortium report, data summary for 2002-2007, issued January 2008. Am J Infect Control 2008;36:627-37.

35. Magill SS, Li Q, Gross C, Dudeck M, Allen-Bridson K, Edwards JR, et al. Incidence and characteristics of ventilator-associated events reported to the national healthcare safety network in 2014. Crit Care Med 2016;44:2154-62.

36. Critical Care Network in North West London - Ventilator care bundle. Available from: http://www.londonccn.nhs.uk/page.asp?fldArea $=1 \&$ fldMenu $=4 \&$ fldSubMenu=4\&fldKey $=186$. $\quad[$ Last accessed on 2017 May 14].

37. Edwards JR, Peterson KD, Andrus ML, Dudeck MA, Pollock DA, Horan TC, et al. National healthcare safety network (NHSN) report, data summary for 2006 through 2007, issued November 2008. Am J Infect Control 2008;36:609-26.

38. Divatia JV, Amin PR, Ramakrishnan N, Kapadia FN, Todi S, Sahu S, et al. Intensive care in India: The Indian intensive care case mix and practice patterns study. Indian J Crit Care Med 2016;20:216-25.

39. Amin N, Divatia J, Agarwal V, Kulkarni A. Readmissions in a surgical Intensive Care Unit: Patient characteristics and outcome. Indian J Crit Care Med 2003;7:14-7.

40. Karthikeyan B, Kadhiravan T, Deepanjali S, Swaminathan RP. Case-mix, care processes, and outcomes in medically-ill patients receiving mechanical ventilation in a low-resource setting from Southern India: A Prospective clinical case series. PLoS One 2015;10:e135336.

41. Mathai AS, Phillips A, Isaac R. Ventilator-associated pneumonia: A persistent healthcare problem in Indian Intensive Care Units! Lung India 2016;33:512-6.

42. Ranjan N, Chaudhary U, Chaudhry D, Ranjan KP. Ventilator-associated pneumonia in a tertiary care Intensive Care Unit: Analysis of incidence, risk factors and mortality. Indian J Crit Care Med 2014;18:200-4.

43. Dasgupta S, Das S, Chawan NS, Hazra A. Nosocomial infections in the Intensive Care Unit: Incidence, risk factors, outcome and associated pathogens in a public tertiary teaching hospital of Eastern India. Indian J Crit Care Med 2015;19:14-20.

44. Datta P, Rani H, Chauhan R, Gombar S, Chander J. Health-care-associated infections: Risk factors and epidemiology from an Intensive Care Unit in Northern India. Indian J Anaesth 2014;58:30-5.

45. Kazi MM, Harshe A, Sale H, Mane D, Minal Y, Chabukswar S. Catheter associated urinary tract infections (CAUTI) and antibiotic sensitivity pattern from confirmed cases of CAUTI in a tertiary care hospital: A prospective study. J Clin Microbiol 2015;4:193.

46. Koenig SM, Truwit JD. Ventilator-associated pneumonia: Diagnosis, treatment, and prevention. Clin Microbiol Rev 2006;19:637-57.

47. Horan TC, Andrus M, Dudeck MA. CDC/NHSN surveillance definition of health care-associated infection and criteria for specific types of infections in the acute care setting. Am J Infect Control 2008;36:309-32.

48. Bloodstream Infection Event (Central Line-Associated Bloodstream Infection and Non-Central Line-Associated Bloodstream Infection). Available from: http://www.cdc.gov/nhsn/PDFs/pscManual/4PSC CLABScurrent.pdf. [Last accessed on 2017 May 15].

49. Urinary Tract Infection (Catheter-Associated Urinary Tract Infection [CAUTI] and Non-Catheter-Associated Urinary Tract Infection [UTI]) and Other Urinary System Infection [USI]) Events. Available from: http://www.cdc.gov/nhsn/pdfs/pscmanual/7psccauticurrent.pdf. [Last accessed on 2017 May 15].

50. Agrawal A, Gandhe M, Gandhe S, Agrawal N. Study of length of stay and average cost of treatment in medicine Intensive Care Unit at tertiary care center. J Health Res Rev 2017;4:24-9.

51. Babu A, Madhavan K, Singhal M, Sagar S, Ranjan P. Pressure ulcer surveillance in neurotrauma patients at a level one trauma centre in India. Oman Med J 2015;30:441-6. 